\title{
GAMBARAN FAKTOR STATUS PEKERJAAN, PENDIDIKAN DAN DUKUNGAN KELUARGA TERHADAP KUNJUNGAN POSYANDU BALITA USIA 0-5 TAHUN DI POSYANDU PEPAYA DUKUH KARANGREJO DESA TEGALREJO KECAMATAN MERAKURAK KABUPATEN TUBAN
}

\author{
Mariyatul Qiftiyah*
}

\section{*Dosen Program Studi Diploma III Kebidanan STIKES Nahdlatul Ulama Tuban}

\begin{abstract}
ABSTRAK
Tingkat kehadiran balita dalam pelaksanaan penimbanagan balita ke posyandu masih jauh dari target bidan desa sebesar $80 \%$. Berdasarkan buku register bidan di posyandu pepaya banyak balita yang tidak berkunjung secara rutin. Berbagai faktor yang mempengaruhi rendahnya kehadiran balita ke posyandu adalah faktor pengetauan, pekerjaan, pendidikan, umur balita, paritas, jarak, dukungan keluarga dan tokoh masyarakat. Tujuan penelitian ini adalah untuk mengetahui gambaran faktor status pekerjaan, pendidikan dan dukungan keluarga terhadap kunjungan posyandu balita usia 0-5 tahun Di Posyandu Pepaya Dukuh Karangrejo Desa Tegalrejo Kecamatan Merakurak Kabupaten Tuban.

Penelitian ini menggunakan desain deskriptif. Populasi penelitian seluruh keluarga balita usia 0-5 tahun di Posyandu Pepaya dukuh Karangrejo desa Tegalrejo Merakurak Tuban sebanyak 73 balita. Tehnik pengambilan sampel menggunakan total sampling dengan jumlah sampel 60 orang. Cara pengumpulan data menggunakan kuesioner dan buku register. Analisis data menggunakan univariat data disajikan dengan bentuk proporsi dan tabel silang.

Hasil penelitian didapatkan bahwa sebagian besar responden bekerja sebanyak 40 $(66,7 \%)$. hampir seluruhnya responden berpendidikan rendah sebanyak 54 (90\%). Sebagian besar responden yang mendapat dukungan cukup sebanyak 31 (52\%). Sebagian besar responden berkunjung tidak rutin sebanyak $40(66,7 \%)$. Sebagian besar kunjungan posyandu balita tidak rutin pada ibu bekerja $26(65 \%)$. Hampir seluruhnya kunjungan posyandu balita tidak rutin berpendidikan rendah sebanyak 37 (92,5\%). Sedangkan sebagian besar kunjungan posyandu balita tidak rutin mendapat dukungan cukup sebanyak $21(52,5 \%)$.

Dari hasil penelitian ini dapat di simpulkan bahwa sebagian besar responden berkunjung tidak rutin karena banyaknya ibu bekerja dan pendidikan rendah. Oleh karena itu diharapkan petugas kesehatan mengadakan kelas ibu balita setiap bulan, memberikan multivitamin setiap datang ke posyandu, dan kegiatan lomba balita pada saat posyandu untuk meningkatkan kunjungan posyandu.
\end{abstract}

Kata Kunci : Status Pekerjaan, Pendidikan, Dukungan Keluarga, Kunjungan Posyandu Balita

\section{PENDAHULUAN}

Posyandu merupakan salah satu Upaya Kesehatan Berbasis Masyarakat yang di kelola dan diselenggarakan dari, oleh, untuk dan bersama masyarakat untuk memberdayakan dan memberikan kemudahan kepada masyarakat guna memperoleh pelayanan kesehatan dasar bagi ibu, bayi dan balita. Keberhasilan posyandu tergambar melalui cakupan
SKDN yaitu : (1) S : Semua balita di wilayah kerja Posyandu. (2) K : Semua balita yang memiliki KMS. (3) D : Balita yang di timbang. (4) $\mathrm{N}$ : Balita yang Berat Badannya naik (Yuniyanti \& Masini, 2016).

Pertumbuhan pada balita dapat dipantau melalui penimbangan berat badan setiap bulan. Pentingnya untuk menimbang balita secara rutin setiap bulan untuk memastikan adanya penambahan berat 
badan yang berarti anak tumbuh baik dan sehat. Rendahnya tingkat kehadiran anak bawah lima tahun (Balita) ke Posyandu. Dilihat dari jumlah anak yang ditimbang dengan seluruh anak yang ada di wilayah tersebut atau D/ S (Tri. L, 2008).

Berdasarkan Data Dinas Kesehatan Provinsi Jawa Timur tahun 2012 angka D/ $S$ tercatat sebesar $72,36 \%$. Pencapaian ini sedikit lebih rendah dibanding dengan pencapaian tahun 2011 sebesar 74,72\%, tetapi di Jawa Timur hampir semua kabupaten/ kota pencapaiannya di atas $60 \%$. Sedangkan pencapaian angka D/ S di Kabupaten Tuban tahun 2012 sebesar 80,57\% (Dinkes Provinsi Jawa Timur, 2012).

Dari data pendahuluan pada bulan Mei 2017 dari hasil wawancara di Posyandu Pepaya Dukuh Karangrejo Desa Tegalrejo Merakurak Tuban dari 10 balita, 4 balita (40\%) yang rutin datang ke Posyandu dengan alasan ibu balita tidak bekerja dan keluarga selalu mengingatkan untuk mengikuti posyandu balita untuk memantau berat badan balita setiap bulan, Sedangkan 6 balita (60\%) tidak rutin datang menimbang balita di posyandu dengan alasan kurangnya informasi tentang terlaksananya posyandu balita karena ibu balita bekerja diluar rumah sehingga tidak ada waktu luang untuk datang di Posyandu. Sedangkan harapan dari pemerintah jumlah kehadiran ibu dalam pelaksanaan penimbanagan balita ke posyandu adalah sebesar $80 \%$.

Menurut teori dari Lawrence Green faktor-faktor yang mempengaruhi rendahnya kunjungan balita ke posyandu antara lain faktor predisposisi : pengetahuan, pendidikan, paritas, umur balita, status pekerjaan. Faktor pemungkin : jarak fasilitas, transportasi dan faktor penguat : tokoh masyarakat, dukungan keluarga (Notoatmodjo, 2014).

Peran ibu yang bekerja dan yang tidak bekerja sangat berpengaruh terhadap perawatan keluarga. Hal ini dapat dilihat dari waktu yang diberikan ibu untuk mengasuh dan membawa anaknya berkunjung ke posyandu masih kurang karena waktunya akan habis untuk menyelesaikan semua pekerjaan, Sedangkan pada ibu rumah tangga memungkinkan mempunyai waktu lebih banyak untuk beristirahat dan meluangkan waktu untuk membawa anaknya ke Posyandu (Husnaini, 2009).

Dukungan keluarga merupakan suatu bentuk hubungan interpersonal yang meliputi sikap, tindakan dan penerimaan terhadap anggota keluarga, sehingga anggota keluarga merasa ada yang memperhatikan.

Dampak yang dialami balita apabila tidak rutin dalam kegiatan penimbangan di Posyandu antara lain tidak mendapat penyuluhan kesehatan, tidak mendapat vitamin $A$, ibu balita tidak mengetahui pertumbuhan dan perkembangan berat badan balita. Hal tersebut yang memicu munculnya permasalahan gizi pada balitanyang akan berdampak sangat fatal yaitu dapat menyebabkan kematian. Untuk itu keluarga harus menimbang balitanya setiap bulan agar terpantau pertumbuhannya (Yuniyanti \& Masini, 2016).

Upaya dalam rangka meningkatkan kunjungan balita ke posyandu desa tegalrejo dengan cara menumbuhkan kesadaran masyarakat khususnya ibu balita tentang pentingnya pelaksanaan kegiatan posyandu bagi balita seperti mengadakan penyuluhan, mengikut sertakan tokoh masyarakat sebagai motivator serta lebih menggiatkan kader dalam mengelola kegiatan posyandu (Yunianti \& Masini, 2016). Memberikan apresiasi berupa hadiah terhadap anaknya yang ditimbang sampai umur 5 tahun, memberikan multivitamin setiap datang ke posyandu, bersikap ramah, dan jadwal penimbangan selalu tepat sehingga sikap ibu balita dalam menimbang anaknya ke posyandu dapat meningkat.

Berdasarkan uraian di dapat di atas, peneliti merasa tertarik tentang gambaran faktor status pekerjaan, pendidikan dan dukungan keluarga terhadap kunjungan 
posyandu balita usia 0-5 tahun di Posyandu Pepaya Dukuh Karangrejo Desa Tegalrejo Merakurak Tuban.

\section{METODE DAN BAHAN}

Dalam penelitian ini, peneliti menggunakan desain penelitian deskriptif.

Populasi dalam penelitian ini sebanyak 73 responden. Sampel daam penelitian ini sebanyak 60 responden. Tehnik pengambilan sampel Total Sampling.

Alat pengumpulan data penelitian ini adalah data primer dan data sekunder. Analisa data penelitian ini menggunakan univariat data disajikan dengan bentuk proporsi dan tabel silang.

\section{HASIL DAN ANALISI PENELITIAN}

Penelitian ini dilakukan di posyandu pepaya dukuh karangrejo desa tegalrejo kecamatan tuban. Pada penelitian ini yang dijadikan responden adalah seluruh keluarga balita usia 0-5 di posyandu pepaya yang hadir atas undangan.

\section{DATA KHUSUS}

1. Status Pekerjaan

Distribusi Responden Berdasarkan Status Pekerjaan di Posyandu Pepaya Dukuh Karangrejo Desa Tegalrejo Kecamatan Merakurak Kabupaten Tuban.

\begin{tabular}{clcc}
\hline No & $\begin{array}{c}\text { Status } \\
\text { Pekerjaan }\end{array}$ & $f$ & $\%$ \\
\hline 1 & Bekerja & 40 & 66,7 \\
2 & Tidak Bekerja & 20 & 33,3 \\
\hline & Jumlah & 60 & 100 \\
\hline
\end{tabular}

Sumber : Data Primer, 2017

Berdasarkan tabel 4.2.1 bahwa sebagian besar responden bekerja sebanyak 40 $(66,7 \%)$.

2. Pendididikan

Distribusi Responden Berdasarkan Pendidikan di Posyandu Pepaya Dukuh Karangrejo Desa Tegalrejo Kecamatan Merakurak Kabupaten Tuban.

\begin{tabular}{clcc}
\hline No & Pendidikan & $f$ & $\%$ \\
\hline 1 & Rendah & 54 & 90 \\
2 & Menengah & 5 & 8,3
\end{tabular}

\begin{tabular}{cccc}
3 & Tinggi & 1 & 1,7 \\
\hline & Jumlah & 60 & 100 \\
\hline
\end{tabular}

Sumber : Data Primer, 2017

Berdasarkan tabel 4.2.2 bahwa hampir seluruhnya responden berpendidikan rendah (SD,SLTP) sebanyak 54 (90\%).

3. Dukungan Keluarga

Distribusi Responden Berdasarkan Dukungan Keluarga di Posyandu Pepaya Dukuh Karangrejo Desa Tegalrejo Kecamatan Merakurak Kabupaten Tuban.

\begin{tabular}{|c|c|c|c|}
\hline No & $\begin{array}{l}\text { Dukungan } \\
\text { Keluarga }\end{array}$ & $f$ & $\%$ \\
\hline 1 & $\begin{array}{l}\text { Kurang Mendapat } \\
\text { Dukungan }\end{array}$ & 8 & 13 \\
\hline 2 & $\begin{array}{l}\text { Mendapat } \\
\text { Dukungan Cukup }\end{array}$ & 31 & 52 \\
\hline 3 & $\begin{array}{l}\text { Mendapat } \\
\text { Dukungan Baik }\end{array}$ & 21 & 35 \\
\hline & Jumlah & 60 & 100 \\
\hline
\end{tabular}

Sumber : Data Primer, 2017 Mean : 70\% Median : 68,75\% Modus : $68.75 \%$

Berdasarkan tabel 4.2.3 bahwa sebagian besar responden yang mendapat dukungan cukup sebanyak 31 (52\%).

4. Kunjungan Posyandu Balita

Distribusi Responden Berdasarkan Kunjungan Posyandu Balita di Posyandu Pepaya Dukuh Karangrejo Desa Tegalrejo Kecamatan Merakurak Kabupaten Tuban.

\begin{tabular}{clcc}
\hline No & Kunjungan & $\boldsymbol{f}$ & $\boldsymbol{\%}$ \\
\hline 1 & Rutin & 20 & 33,3 \\
2 & Tidak Rutin & 40 & 66,7 \\
\hline & Jumlah & 60 & 100 \\
\hline
\end{tabular}

Sumber: Data Sekunder, 2017 Mean:

<4x Median: 3x Modus : $<4 x$

Berdasarkan tabel 4.2.4 bahwa sebagian besar responden berkunjung tidak rutin sebanyak $40(66,7 \%)$.

5. Kunjungan Posyandu Balita berdasarkan status pekerjaan

Distribusi Kunjungan Posyandu Balita Berdasarkan Status Pekerjaan Di Posyandu Pepaya Dukuh Karangrejo Desa Tegalrejo Merakurak Tuban. 


\begin{tabular}{lccc}
\hline $\begin{array}{c}\text { Kunjungan } \\
\text { Posyandu } \\
\text { Balita }\end{array}$ & \begin{tabular}{c} 
Status Pekerjaan \\
\cline { 2 - 3 } a
\end{tabular} & $\begin{array}{c}\text { Jumlah } \\
\text { Tidak } \\
\text { Bekerj } \\
\mathbf{a}\end{array}$ \\
\hline Rutin & 9 & 11 & 20 \\
& $(45 \%)$ & $(55 \%)$ & $(100 \%)$ \\
Tidak Rutin & 26 & 14 & 40 \\
& $(65 \%)$ & $(35 \%)$ & $(100 \%)$ \\
\hline Jumlah & 35 & 24 & 60 \\
& $(58,3 \%$ & $(60 \%)$ & $(100 \%)$ \\
& & & \\
\hline
\end{tabular}

Sumber : Data Primer, 2017

Pada tabel 4.2.5 menunjukkan bahwa sebagian besar kunjungan posyandu balita tidak rutin pada ibu bekerja sebanyak 26 (65\%). Sedangkan setengahnya kunjungan posyandu balita rutin pada ibu tidak bekerja sebanyak 11 (55\%).

6. Kunjungan Posyandu Balita berdasarkan pendidikan

Distribusi Kunjungan Posyandu Balita Berdasarkan Pendidikan Di Posyandu Pepaya Dukuh Karangrejo Desa Tegalrejo Merakurak Tuban.

\begin{tabular}{|c|c|c|c|c|}
\hline \multirow{2}{*}{$\begin{array}{c}\text { Kunjunga } \\
\text { n } \\
\text { Posyandu } \\
\text { Balita } \\
\end{array}$} & \multicolumn{3}{|c|}{ Pendidikan } & \multirow{2}{*}{$\begin{array}{c}\text { Jum } \\
\text { lah }\end{array}$} \\
\hline & $\begin{array}{c}\text { Renda } \\
\mathbf{h}\end{array}$ & $\begin{array}{c}\text { Men } \\
\text { enga } \\
h\end{array}$ & $\underset{\mathbf{i}}{\text { Tingg }}$ & \\
\hline Rutin & $\begin{array}{c}17 \\
(85 \%)\end{array}$ & $\begin{array}{c}2 \\
(10 \\
\%)\end{array}$ & $\begin{array}{c}1 \\
(5 \%)\end{array}$ & $\begin{array}{c}20 \\
(100 \\
\%)\end{array}$ \\
\hline Tidak & 37 & 3 & 0 & 40 \\
\hline Rutin & $\begin{array}{c}(92,5 \% \\
\quad\end{array}$ & $(8 \%)$ & $(0 \%)$ & $\begin{array}{c}(100 \\
\%)\end{array}$ \\
\hline Jumlah & $\begin{array}{c}54 \\
(90 \%)\end{array}$ & $\begin{array}{c}5 \\
(8,3 \\
\%)\end{array}$ & $\begin{array}{c}1 \\
(1 \%)\end{array}$ & $\begin{array}{c}60 \\
(100 \\
\%)\end{array}$ \\
\hline
\end{tabular}

Sumber : Data Primer, 2017

Pada tabel 4.2.6 menunjukkan kunjungan posyandu balita tidak rutin berpendidikan rendah sebanyak 37 $(92,5 \%)$. Sebagian kecil kunjungan posyandu balita rutin berpendidikan menengah sebanyak 2 (10\%).
7. Kunjungan Posyandu Balita berdasarkan dukungan keluarga

Distribusi Kunjungan Posyandu

Balita Berdasarkan Dukungan

Keluarga Di Posyandu Pepaya Dukuh

Karangrejo Desa Tegalrejo Merakurak Tuban.

\begin{tabular}{|c|c|c|c|c|}
\hline Kunj & Duk & ngan Kelu & Irga & \\
\hline unga & $\underset{\mathrm{g}}{\text { Kuran }}$ & $\begin{array}{c}\text { Mendap } \\
\text { at }\end{array}$ & $\begin{array}{c}\text { Mend } \\
\text { apat }\end{array}$ & $\begin{array}{c}\text { Jumla } \\
\mathbf{h}\end{array}$ \\
\hline $\begin{array}{c}\text { Posya } \\
\text { ndu }\end{array}$ & $\begin{array}{l}\text { Menda } \\
\text { pat }\end{array}$ & $\begin{array}{c}\text { Dukung } \\
\text { an }\end{array}$ & $\begin{array}{c}\text { Duku } \\
\text { ngan }\end{array}$ & \\
\hline Balita & $\begin{array}{c}\text { Dukun } \\
\text { gan }\end{array}$ & Cukup & Baik & \\
\hline Rutin & $\begin{array}{c}2 \\
(10 \%)\end{array}$ & $9(45 \%)$ & $\begin{array}{c}9 \\
(45 \%)\end{array}$ & $\begin{array}{c}20 \\
(100 \%)\end{array}$ \\
\hline Tidak & 7 & 21 & 12 & 40 \\
\hline Rutin & $\begin{array}{c}(17,5 \% \\
)\end{array}$ & $(52,5 \%)$ & $(30 \%)$ & $(100 \%)$ \\
\hline $\begin{array}{l}\text { Jumla } \\
\mathrm{h}\end{array}$ & $\begin{array}{c}9 \\
(15 \%) \\
\end{array}$ & $30(50 \%)$ & $\begin{array}{c}21 \\
(35 \%) \\
\end{array}$ & $\begin{array}{c}60 \\
(100 \%) \\
\end{array}$ \\
\hline $\begin{array}{l}\text { Sumbe } \\
\text { Mediar } \\
\text { Pad } \\
\text { sebagi } \\
\text { tidak } \\
\text { sebany } \\
\text { seteng } \\
\text { rutin } n \\
\text { sebany }\end{array}$ & $\begin{array}{l}\text { Data } \\
: 68,75 \\
\text { tabel } \\
\text { n besar } \\
\text { utin m } \\
\text { k } 21 \\
\text { hnya ku } \\
\text { endapat } \\
\text { k } 21(52\end{array}$ & $\begin{array}{l}\text { rimer, } 201 \\
\text { Modus : } 7 \\
2.7 \text { menur } \\
\text { unjungan } \mathrm{p} \\
\text { dapat du } \\
(52,5 \%) \\
\text { jungan p } \\
\text { lukungan o }\end{array}$ & $\begin{array}{l}\text { Mean } \\
\% \\
\text { ukkan } \\
\text { syandu } \\
\text { ungan } \\
\text { seda } \\
\text { syandu } \\
\text { kup dar }\end{array}$ & $\begin{array}{l}70 \% \\
\text { ahwa } \\
\text { balita } \\
\text { ukup } \\
\text { gkan } \\
\text { balita } \\
\text { baik }\end{array}$ \\
\hline
\end{tabular}

\section{PEMBAHASAN}

\section{Identifikasi Status Pekerjaan Ibu Balita}

Berdasarkan tabel 4.2.1 didapatkan dari 60 responden yang diteliti bahwa sebagian besar responden bekerja sebanyak $40(66,7 \%)$.

Bekerja adalah mereka yang melakukan suatu pekerjaan dengan maksud memperoleh pendapatan atau keuntungan (Suryani, 2009).

Menurut thomas yang di kutip Nursalam (2003) Pekerjaan adalah keburukan yang dilakukan terutama untuk menunjang kehidupannya dan kehidupan keluarga. Pekerjaan bukanlah menjadi sumber kesenangan, tetapi lebih banyak merupakan cara mencari nafkah yang membosankan, berulang dan banyak 
tantangan. Sedangkan bekerja umumnya merupakan kegiatan yang menyita waktu. Bekerja bagi ibu-ibu akan memmpunyai pengaruh terhadap kehidupan keluarga (Wawan, 2010)

Dari uraian diatas didapatkan hasil sebagian besar ibu balita dengan status bekerja, ibu bekerja menyebabkan tidak membawa anaknya ke posyandu untuk ditimbang dikarenakan faktor kesibukan dan ketidaktersediaan waktu. Bahwa seseorang yang mempunyai pekerjaan dengan waktu yang cukup padat akan mempengaruhi ketidakhadiran dalam pelaksanaan posyandu. Orang tua tidak mempunyai waktu luang, sehingga semakin tinggi aktivitas pekerjaan orang tua semakin sulit datang ke posyandu.

Dari penelitian ini di dapatkan hasil sebagian besar ibu dengan status bekerja lebih banyak dari pada responden yang tidak bekerja. Hal ini dapat dilihat dari waktu yang diberikan ibu untuk mengasuh dan membawa anaknya berkunjung ke posyandu masih kurang karena waktunya akan habis untuk menyelesaikan semua pekerjaannya. Jika dikaitkan dengan teori diatas hasil yang didapatkan peneliti adalah sesuai. Diperkirakan karena ibu yang bekerja tidak bisa mengatur waktu sehingga mengasuh anaknya tidak ada, sehingga tidak mempunyai waktu luang datang secara rutin ke posyandu, berbeda dengan ibu yang tidak bekerja (ibu rumah tangga) yang mempunyai banyak waktu luang untuk berkunjung secara rutin ke posyandu. Dan jadwal kegiatan posyandu di mulai pada jam 09.00- 12.00 WIB pada waktu tersebut ibu-ibu balita sudah mulai bekerja sehingga tidak bisa datang ke posyandu untuk mengantarkan balitanya. Dari penelitian yang saya dapat sebagian besar penduduk desa tegalrejo bekerja sebagai petani.

\section{Identifikasi Pendidikan Ibu Balita}

Berdasarkan tabel 4.2.2 didapatkan dari 60 responden yang diteliti bahwa hampir seluruhnya responden berpendidikan rendah (SD,SLTP) sebanyak 54 (90\%).
Pendidikan berarti bimbingan yang diberikan seseorang terhadap perkembangan orang lain menuju ke arah cita-cita tertentu yang menetukan manusia untuk berbuat dan mengisi kehidupan untuk mencapai keselamatan dan kebahagiaan. Pendidikan diperlukan untuk mendapat informasi misalnya hal-hal yang menunjang kesehatan sehingga dapat meningkatkan kualitas hidup. Menurut YB Mantra yang dikutip Notoadmodjo (2003) pendidikan dapat mempengaruhi seseorang termasuk juga perilaku seseorang akan pola hidup terutama dalam memotivasi untuk sikap berperan serta dalam pembangunan. Pada umumnya makin tinggi pendidikan seseorang makin mudah menerima informasi (Wawan, 2010).

Dari uraian diatas dapat dijelaskan bahwa hampir seluruhnya responden berpendidikan rendah daripada berpendidikan tinggi. hal ini sesuai dengan teori di atas. Pendidikan yang berpengaruh pada pola pikir seseorang dimana yang pendidikan dasar/ rendah kemungkinan pengetahuannya terbatas. Seseorang dengan pendidikan yang rendah akan menghambat perkembangan sikap seseorang terhadap perubahan-perubahan hidup sehat termasuk berkaitan dengan pemahaman mengenai pentingnya melakukan kunjungan ke posyandu untuk memantau kesehatan dan perkembangan anak (Notoadmodjo, 2010). Maka dari itu perlu adanya peningkatan pemahaman ibu tentang manfaat posyandu melalui sarana media informasi seperti poster, leaflet, spanduk dll.

\section{Identifikasi Dukungan Keluarga Ibu Balita}

Berdasarkan tabel 4.2.3 didapatkan dari 60 responden yang diteliti bahwa bahwa setengahnya responden yang mendapat dukungan cukup sebanyak 31 $(52 \%)$.

Dukungan keluarga adalah sikap, tindakan penerimaan keluarga terhadap anggota keluarganya, berupa dukungan informasional, dukungan penilaian, dukungan instrumental dan dukungan 
emosional. Jadi dukungan keluarga adalah suatu bentuk hubungan interpersonal yang meliputi sikap, tindakan dan penerimaan terhadap anggota keluarga, sehingga anggota keluarga merasa ada yang memperhatikan (Friedman, 2010). Keluarga merupakan sistem dasar dimana perilaku sehat dan perawatan kesehatan diatur, dilakukan dan diamankan keluarga memberikan perawatan kesehatan bersifat dan bersama-sama merawat anggota keluarga. Keluarga memiliki tanggung jawab utama untuk memulai dan mengkoordinasikan pelayanan yang diberikan oleh petugas kesehatan (Nofianti, 2012).

Dari uraian diatas setengahnya responden mendapat dukungan cukup, bahwa pada umumnya ibu balita mendapat dukungan dari keluarga. Hal ini disebabkan karena sikap keluarga yang cukup baik terhadap kesehatan sehingga merasa perlu untuk terlibat dalam menjaga kesehatan anaknya, salah satunya adalah dengan cara mengingatkan ibu untuk selalu datang ke posyandu. Keluarga yang aktif adalah keluarga yang rutin membawa anaknya ke posyandu setiap bulan. Sesibuk apapun orang tua perlu menyempatkan diri satu bulan sekali ke posyandu. Jika orang tua tidak tidak sempat ke posyandu maka tidak ada salahnya meminta bantuan keluarga atau pengasuh untuk mengantarkan anak ke posyandu. Posyandu bukan hanya tempat untuk mendapat imunisasi saja tetapi juga memantau pertumbuhan berat badan, deteksi dini penyimpanan pertumbuhan dan perkembangan anak.

\section{Identifikasi Kunjungan Posyandu Balita}

Berdasarkan tabel 4.2.4 didapatkan dari 60 responden yang diteliti bahwa sebagian besar responden berkunjung tidak rutin sebanyak $40 \quad(66,7 \%)$, sedangkan hampir setengahnya $(33,3 \%)$ responden berkunjung tidak rutin.

Adapun faktor-faktor yang mempengaruhi kunjungan balita secara rutin datang ke posyandu adalah status pekerjaan umumnya merupakan kegiatan yang menyita waktu. Bekerja bagi ibu-ibu akan mempunyai pengaruh terhadap kehidupan keluarga. Pendidikan dapat mempengaruhi seseorang termasuk juga perilaku seseorang akan pola hidup terutama dalam memotivasi untuk sikap berperan serta dalam pembangunan. pada umumnya makin tinggi pendidikan seseorang makin mudah menerima informasi (Wawan, 2010). Dukungan keluarga adalah suatu bentuk hubungan interpersonal yang meliputi sikap, tindakan dan penerimaan terhadap anggota keluarga, sehingga anggota keluarga merasa ada yang memperhatikan (Friedman, 2010). Dikatakan rutin apabila minimal $4 \mathrm{x}$ anak ditimbang secara berturut-turut selama 6 bulan terakhir. Dikatakan tidak rutin apabila minimal $<4 \mathrm{x}$ anak ditimbang secara berturut-turut selama 6 bulan terakhir (Depkes RI, 2007).

Dari penelitian di atas didapatkan hasil bahwa sebagian besar responden berkunjung tidak rutin. Rutin tidaknya ibu memposyandukan balitanya dipengaruhi oleh peran orang tua. Apabila orang tua rutin membawa balitanya dalam kunjungan posyandu upaya penjaringan yang menentukan penyimpanganpenyimpangan tumbuh kembang balita dan upaya pencegahan secara dini dapat dilakukan.

\section{KESIMPULAN}

1. Sebagian besar ibu balita di Posyandu Pepaya Dukuh Karangrejo Desa Tegalrejo Merakurak Tuban lebih banyak bekerja.

2. Hampir seluruhnya ibu balita di Posyandu Pepaya Dukuh Karangrejo Desa Tegalrejo Merakurak Tuban berpendidikan rendah (SD,SLTP).

3. Sebagian besar di Posyandu Pepaya Dukuh Karangrejo Desa Tegalrejo Merakurak Tuban responden mendapat dukungan cukup.

4. Sebagian besar di Posyandu Pepaya Dukuh Karangrejo Desa Tegalrejo 
Merakurak Tuban responden berkunjung tidak rutin.

5. Sebagian besar berdasarkan status pekerjaan kunjungan balita di Posyandu Pepaya Dukuh Karangrejo Desa Tegalrejo Merakurak Tuban lebih banyak bekerja dengan kunjungan tidak rutin.

6. Hampir seluruhnya berdasarkan pendidikan kunjungan balita di Posyandu Pepaya Dukuh Karangrejo Desa Tegalrejo Merakurak Tuban lebih banyak berpendidikan rendah

7. Sebagian besar berdasarkan dukungan keluarga kunjungan balita di Posyandu Pepaya Dukuh Karangrejo Desa Tegalrejo Merakurak Tuban lebih banyak mendapat dukungan cukup dengan berkunjunga tidak rutin.

\section{SARAN}

\section{Bagi Peneliti}

Diharapkan dapat memberikan penambahan wawasan dalam penulisan ilmiah, serta sebagai masukan mengenai faktor-faktor yang mempengaruhi kunjungan posyandu balita.

\section{Bagi Institusi Pendidikan}

Diharapkan dapat menambah literatur perpustakaan sehingga dapat digunakan sebagai bahan pembanding untuk melakukan penelitian selanjutnya.

\section{Bagi Masyarakat}

Diharapkan dapat digunakan untuk membantu meningkatkan kunjungan posyandu di daerah penelitian.

\section{DAFTAR PUSTAKA}

Arikunto, Suharsini. 2007. "Prosedur Penelitian Suatu Pendekatan Praktik Edisi Revisi V'I. Jakarta: PT Rineka Cipta

Chorunisa. 2009. "Panduan Terpenting Merawat Bayi Dan Balita”. Buku Ajar Keperawatan Anak. EGC. Jakarta
Dinas Kesehatan Provinsi Jawa Timur (2012). "Profil Kesehatan Provinsi Jawa Timur”.http://www.depkes.go.id

Depkes. 2007. "Rencana Pembangunan Kesehatan Menuju Indonesia Sehat". 2010. Jakarta

Depkes. 2008. "Pedoman Umum Pengelolaan Posyandu”. Jakarta : Depkes RI

Dewi, Wawan, A, (2011). "Teori \& Pengukuran Pengetahuan, Sikap, dan Perilaku Manusia. Nuha Medika". Yogyakarta

Friedman, Marilyn M. (2010). "Buku Ajar Keperawatan Keluarga : Riset Teori Dan Prakti"k. EGC. Jakarta

Hidayat, Aziz Alimul, (2010). "Metode Penelitian Kebidanan Tehnik Analisis Data”. Salemba Medika. Jakarta

Husaini, (2009). Hubungan antara Pengetahuan dan Motivasi Kader Posyandu dengan Keaktifan Kader Posyandu di Desa Dukuh Tengah Kecamatan Ketanggungan Kabupaten Brebes. Jawa Tengah : Brebes

Ismawati S, Cahyo, (2010). "Posyandu dan Desa Siaga”. Nuha Medika. Bantul

Kurnia, Nita. 2011. Faktor-Faktor Yang Berhubungan Dengan Partisipasi Ibu Balita Dalam Pemanfaatan Pelayanan Gizi Balita Di Posyandu Kelurahan Sukasari Kecamatan Tangerang Kota Tangerang. Skripsi. Program Studi Kesehatan Masyarakat Fakultas Kedokteran dan Ilmu Kesehatan Unirvesitas Islam Negeri Syarifudin Hidayatullah Jakarta.

Khomsan. (2007). Study Implementasi Program Gizi : Pemanfaatan, Cakupan Keefektifan Dan Dampak Status Gizi. Departemen Gizi Masyarakat. Bogor 
Mubarok, Aziz, (2012). "Ilmu Kesehatan Masyarakat”. Salemba Medika. Jakarta

Nofianti, Susi. (2012). Faktor-faktor yang berhubungan dengan perilaku pemanfaatan posyandu oleh ibu balita di wilayah kerja puskesmas.

Notoadmodjo, Soekidjo. (2010). "Pendidkan promosi \& perilaku kesehata" $n$. Cetakan II. Jakarta

Nursalam, (2014). "Metode Penelitian Ilmu Keperawatan”. Salemba Medika. Jakarta

Oktiawati, Anisa, dkk, (2016). "Pedoman Pelaksanaan Posyandu”. Nuha Medika. Yogyakarta

Retnaningsih. 2013. "Akses Layanan Kesehatan". Raja Grafindo Persada. Jakarta

Rumpiati, (2011). Candidate Role Correlation to Toddlers Visiting Posyandu (Research at Winongo Manguharjo Village Madiun 2011) (50:54)

Sugiyono. (2010). "Metode Penelitian Kuantitatif Kualitatif dan R\&D”. CV Alfabeta. Bandung

Suparyanto. 2012. Konsep Dukungan Keluarga. Di akses 15 Januari 2012 Pukul $\quad 18.00 \quad$ WIB. http:/drsuparyanto.blogspot.com.

Tri L, Dyahsuslam. 2008. Faktor-faktor yang berhubungan dengan tindakan ibu untuk membawa balita ke posyandu di Desa Benda dan Merak, Kecamatan Balareja Kabupaten Tangerang tahun 2007. Depok : Fakultas Kesehatan Masyarakat. Universitas Indonesia.

UNICEF. 2007. Progress for Children. http://www.unicef.org/progressforchildr en/2007n6/index_41505.htm.
Poedji, Sri. (2010). Posyandu Sebuah Konsep Pendekatan Hak Anak dan Perempuan. Di akses 5 April 2009, http://www.indomedia.com

Yuniyanti, Bekti. (2016). "Asuhan Kebidanan Komunitas". Trans medika. Yogyakarta

Februari 2010 